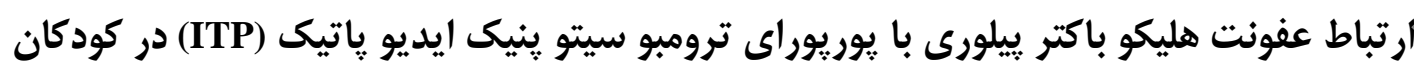

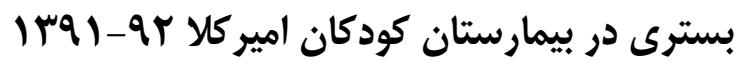

\author{
على محما يوز مير " '، هيوا ملك زاده '، احمد تمدنى'، حسن محمودى '
}

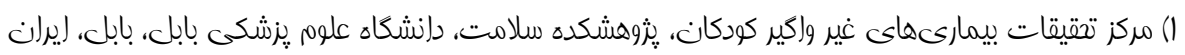

$$
\text { تاريخ دريافت: س ب// }
$$

\section{جكيده}

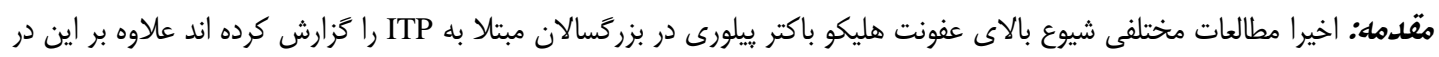

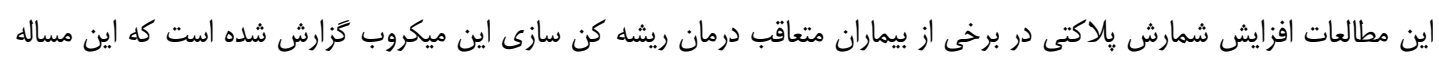
نقش احتمالى هليكو باكتر بيلورى در بروز

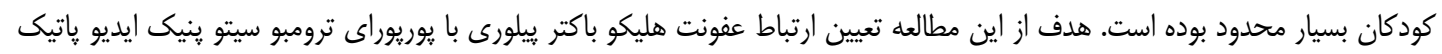

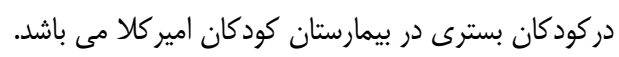

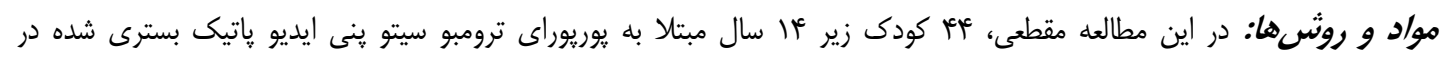

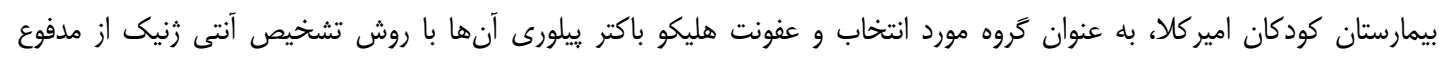

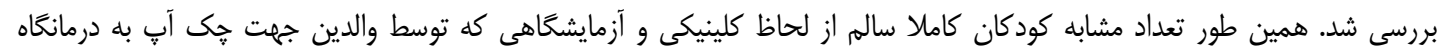

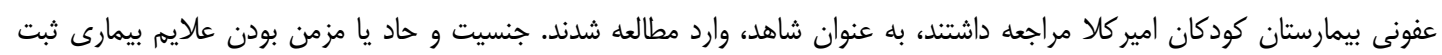

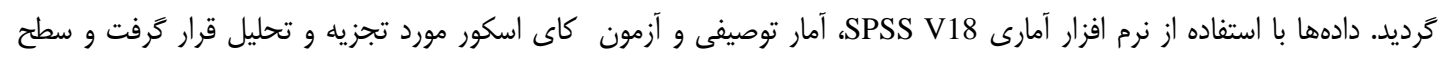

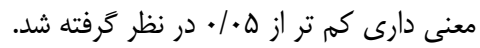

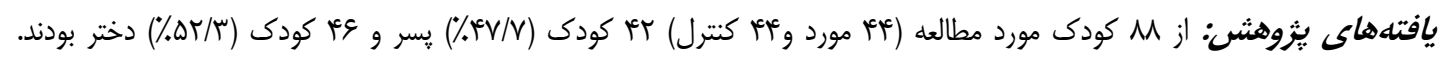

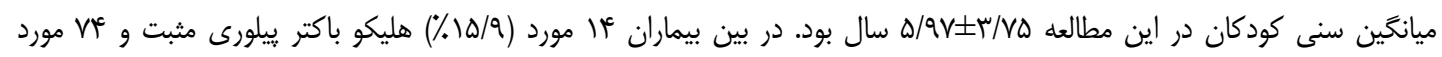

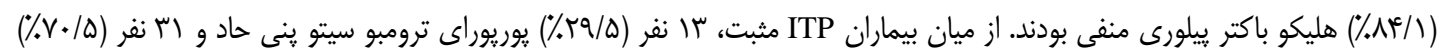

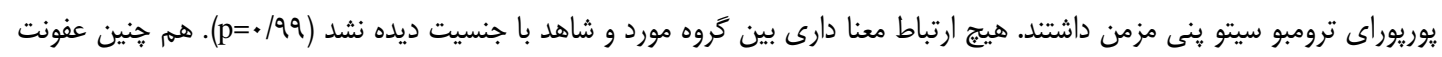
هليكو باكتر ييلورى در دو كروه نيز اختلاف معنا دارى نداشت (p=)/WV).

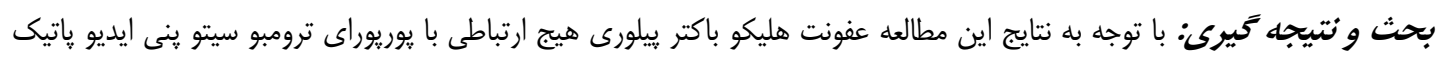
از لحاظ آمارى ندارد.

وازههاى كليدى: هليكو باكتر ييلورى، يوريوراى ترومبو سيتو ينيك ايديو پاتيك، ترومبو سيتو ينى، كودكان

$$
\text { *نويسنده مسئول: مركز تحقيقات بيمارىهاى غير واكير كودكان، يُوهشكده سلامت، دانشَاه علوم يزشكى بابل، بابل، ايران }
$$

Email: alimmir41@gmail.com

Copyright (C) 2017 Journal of Ilam University of Medical Science. This is an open-access article distributed under the terms of the Creative Commons Attribution international 4.0 International License (https://creativecommons.org/licenses/by/4.0/) which permits copy and redistribute the material, in any medium or format, provided the original work is properly cited. 
كند در پاتوزنسيته تظاهرات مختلف بالينى ناشى از اين

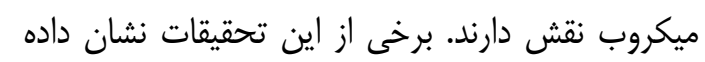

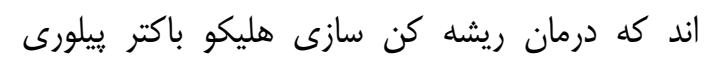

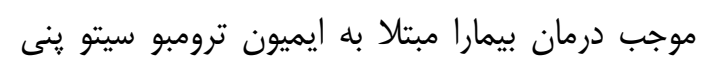

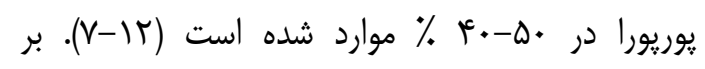
عكس برخى از تحقيقات فراوانى هليكو باكتر ييلورى

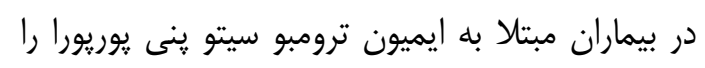

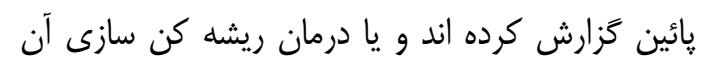

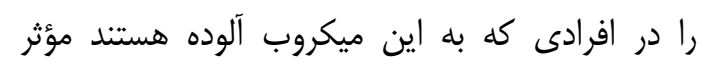

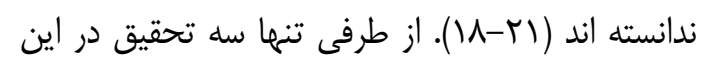

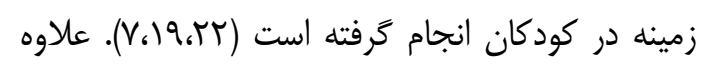

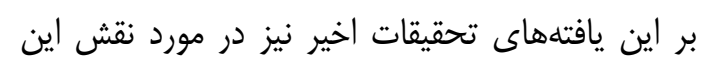

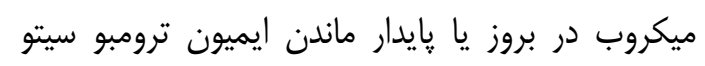

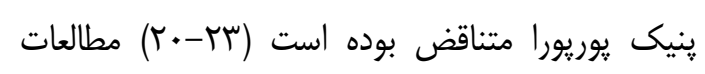
معدودى در ايران صورت گرفته است كه در محدوده سنى بزرگسالان بوده است (IV) عفونت هليكو باكتر

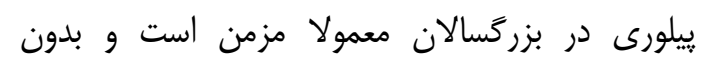
درمان اختصاصى بهببود نمى يابد ولى در در كودكان

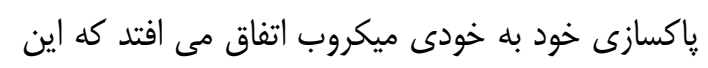

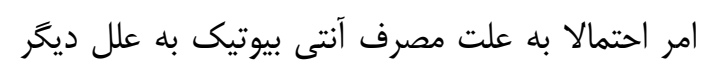

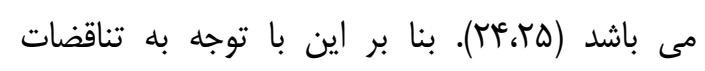

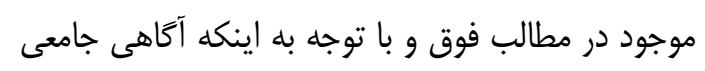
از خضور هليكو باكتر ييلورى ( Helicobacter (pylori

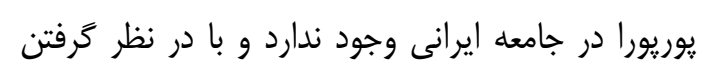

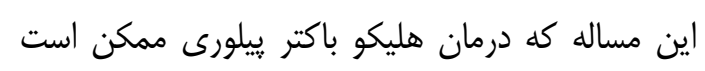

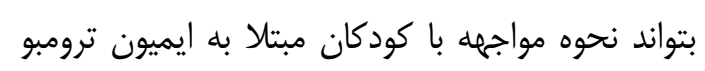

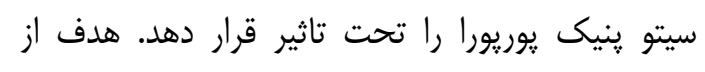
انجام اين مطالعه تعيين ارتباط عفونت هليكو باكتر بتريك

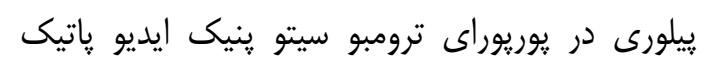

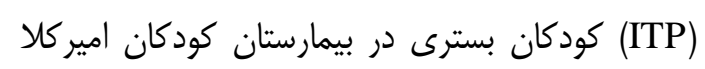
جهت بررسى علت احتمالى يا عامل وابسته و تشديد

$$
\text { كننده آن مى باشد. }
$$

\section{مواد و روش ها}

يزوهش اخير، يك مطالعه تحليلى، از نوع مورد-

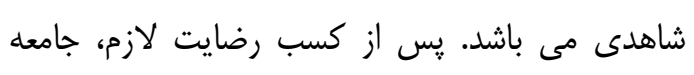

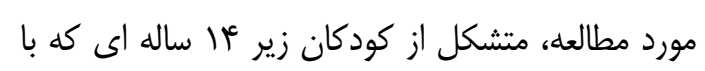

\section{مقدمه}

ايميون ترومبو سيتوينيك يوريورا شايع ترين اختلال اتو

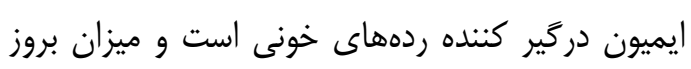

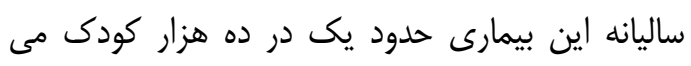

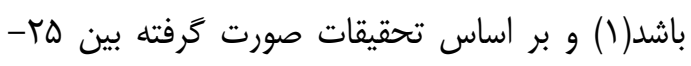

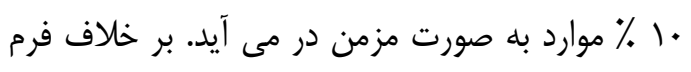

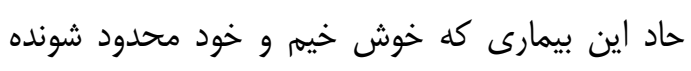

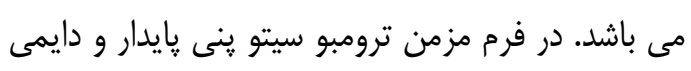

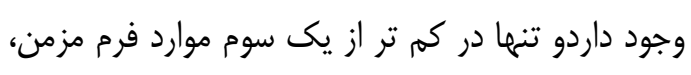

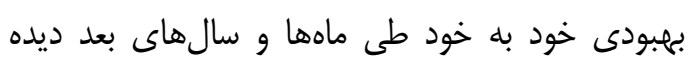

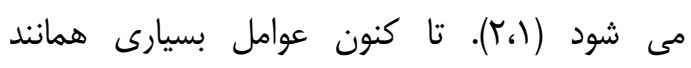
ويروس ها، واكسيناسيون، عوامل زنتيكى و نقص ايمنى تانى

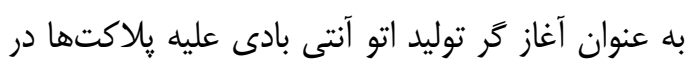

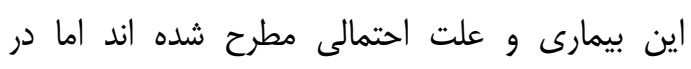
بسيارى از مواردعلت بيمارى نا شناخته باقى مانى إندا

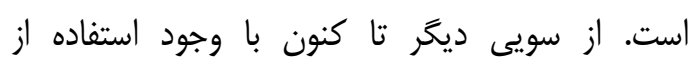

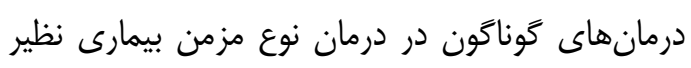

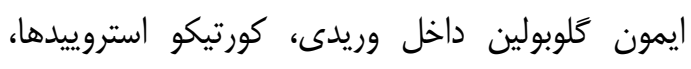
دانازول، داروهاى سركوب كننده سيستم ايمنى (سيكلو سيورين، آزلاتيويرين)، سيكلو فسفاميد، آلكالوييدهاى ائي (سيكاي

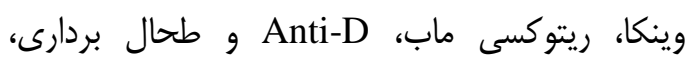

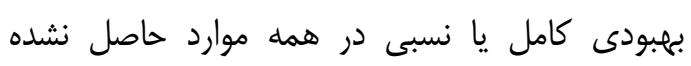

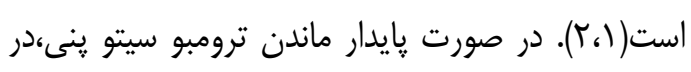
معرض خطر خونريزىهاى تهلديد كننده حيات نظير

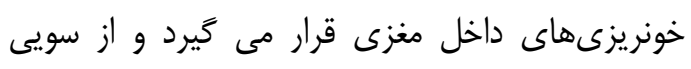

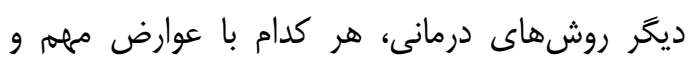
جدى نظير عفونت، سركوب مغز استخوان، سركوب داب سيستم ايمنى و نارسايى كليوى و يا كبدى عمدي همراه

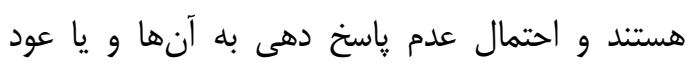

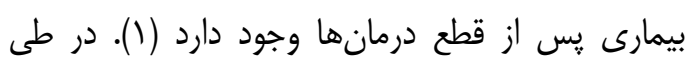
سالهاى اخير تحقيقات بسيارى الودگى با هليكو باكتر

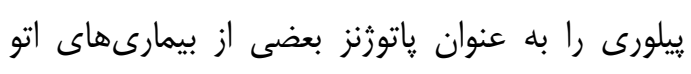

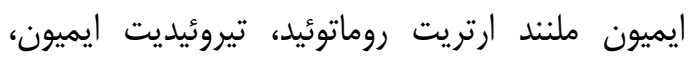

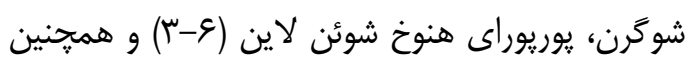

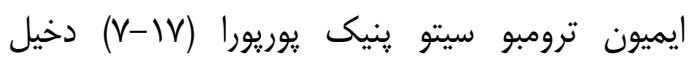

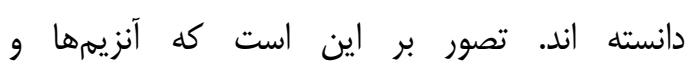

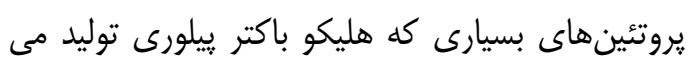


بيماران نبايد در طى يك ماه كذشته تحت درمان با آنتى بيوتيك قرار كرفته باشند.

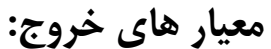

1- مصرف دارو يا داروهايى كه به نوعى در درمان عفونت هليكو باكتر ييلورى كاربرد دارند (صرف نظر از ابتلا يا عدم ابتلاى آنان

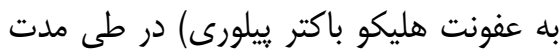

$$
\text { r- هياتو اسبلنو مخالى زيخيرى. }
$$

ب- بيمارىهاى شناخته شده مادر زادى يا اكتسابى كه باعث كاهش يلاكت خون مى شوند مثل لويوس، نقايص ايمنى مادر زادى، لوسمى، لنفوم، سندرم TAR

(Thrombocytopenia-absent radius) حجم نمونه متشكل ازكليه بيماران مراجعه كننده و بسترى در بخش خون بيمارستان كودكان اميركلا با

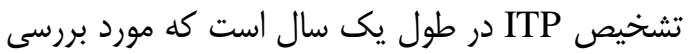

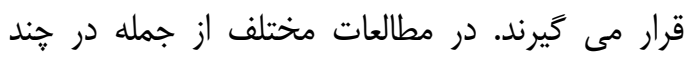

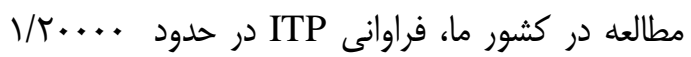
كودكان مىباشد و با توجه به فراوانى • ٪\% روند ازمان در كودكان و اين كه در مطالعات صورت كرفته ميزان فراوانى عفونت هليكو باكتر ييلورى در بين

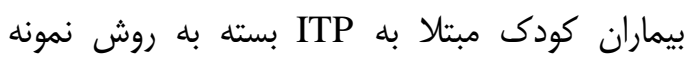
كَيرى و محل انجام مطالعه بين rاتا بr درصد (به طور متوسط Vادرصد) گزارش شده است. با احتساب اين آمار، حداقل تعداد نمونههاى لازم براى انجام اين مطالعه عأ نفر ودر مجموع M د نفر تعيين شد. يس از شناسايى بيماران مبتلا به ITP واجد شرايط

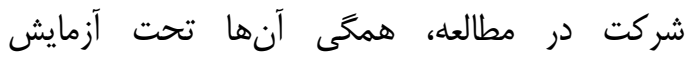
تشخيصى هليكو باكتر ييلورى قرار كرفتند. از بين آناين

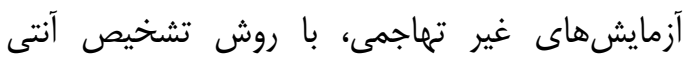
زنيك antigen detection test (كه حساسيت و و اختصاصى بودن آن براى تشخيص عفونت هليكو باكتر

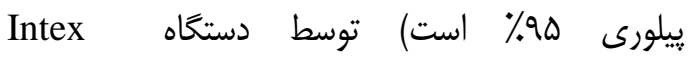
مان Diagnostika

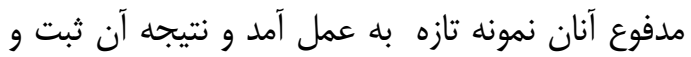
بررسى آمارى شد. هم زمان از تعداد مشابه كودكان

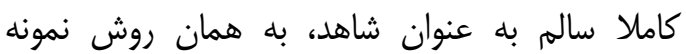
مدفوع كرفته شده و اطلاعات جمع آورى شده بان بان روش نمانه
ضايعات يوستى يا مخاطى خونريزى دهنده مثل يتشى و يوريورا مراجعه كرده اند كه توسط متخصصين هماتو لوزى بر اساس مدارى راهنماى موجود در American Societyof Hematology guideline كم تر از (10. همراه با ESR وWBC Hb, طبيعى، r- داشتن g BMA(Bone Marrow Aspiration) ITP بـ نفع BMB(Bone Marrow Biopsy)

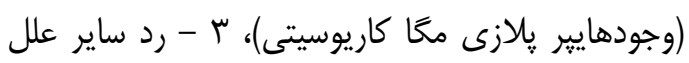
هماتو لوزيك ترومبو سيتو ينى (نظير حالات ميلو يرو

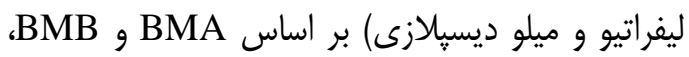
ז- عدم مصرف داروهايى كه به طور بالقوه مىتوانند

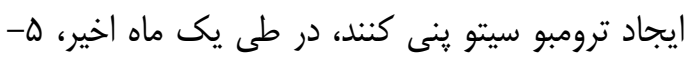

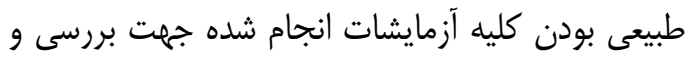
رد دركيرى كبدى، نارسايى كليه و عفونتها شامل: HBs Ag ,HCV Ab ,HIV Ab تشخيص يوريوراى ترومبو سيتو ينى بدون علت واضح (ايديو پاتيك) در بيمارستان كودكان اميركلا بسترى ترون

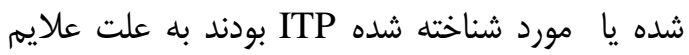

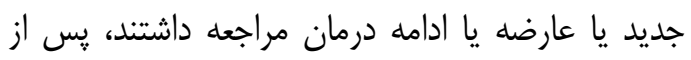
مراجعه به بيمارستان با ارائه فرمهاى اطلاعاتى كه بـ بله صورت جیى ليست طرح تحقيقاتى بودند به آنها و هم

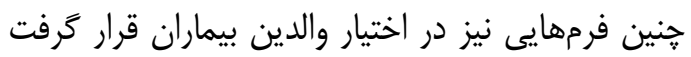
با اين مضامين كه آزمايشهاى انجام شده بر بر روى رولين

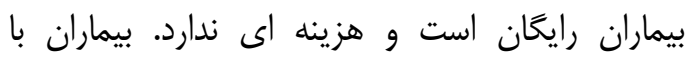
مراجعه به آزمايشگاه رازى بابل از نظر عفونت هليكو

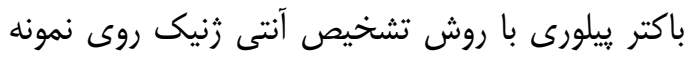

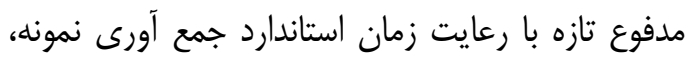
سنجش شدند و با ثبت نتايج نيز مطالعات آمارى انجام إن أندان

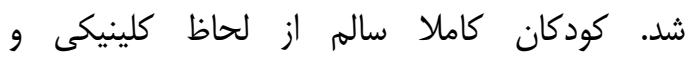

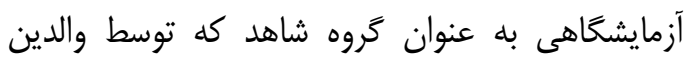
جهت جیى آب به درمانكاه عفونى بيمارستان كودكان

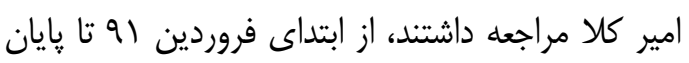
فروردين بو با توجه به معيارهاى ورود و خروج نيز وارد مطالعه شدند. معيار وروود: سن اين بيماران كم تر از عال سال تمام باشد (بزرگسالان وارد مطالعه نشوند) 


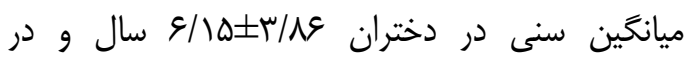

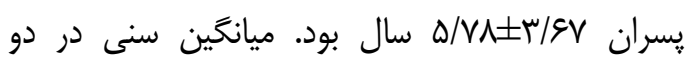
جنس دختر و پِسر هيج اختلاف معنا دارى نداشت

$$
\text { ( } \left.\mathrm{p}=\cdot \mid q)^{\mathrm{c}}\right)
$$

ميانگين سنى در گروه هليكو باكتر يبلورى مثرى مثبت

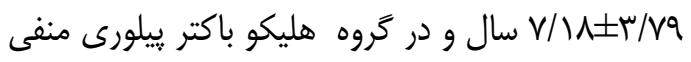

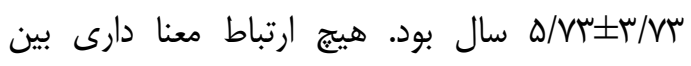

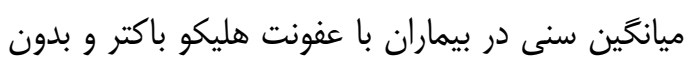
عفونت ديده نشد (p=/T) (نمودار ()).

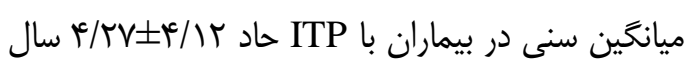

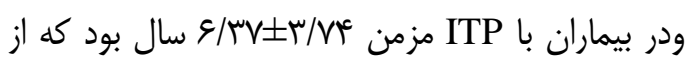

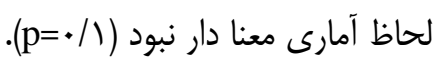
يوريوراى ترومبو سيتو ينى حاد در بيمارانى كه عفونت

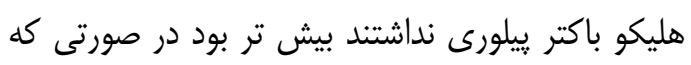

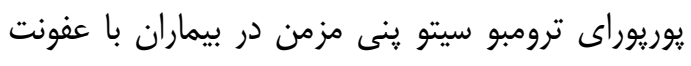
هليكو باكتر ييلورى بيش تر ديده شد(نمودار r).
استفاده از آزمونهاى آمارى مورد تجزيه و تحليل قرار كرفت.

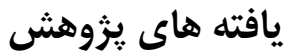

در مجموع M Mودى زير عالها سال وارد مطالعه شدند.

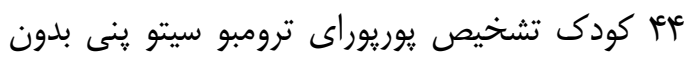
علت واضح (ايديو ياتيك) داشتند و عأ كودى ديخر

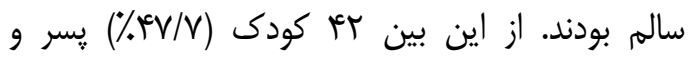

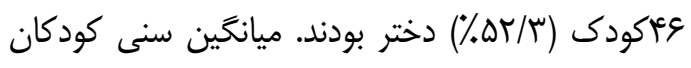
در اين مطالعه Q/Y

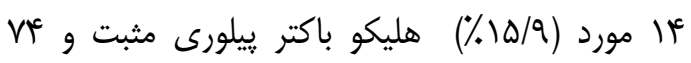

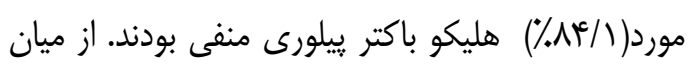

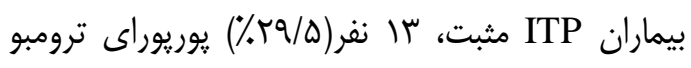

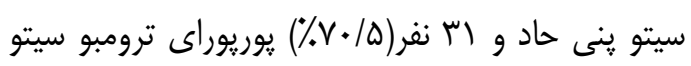

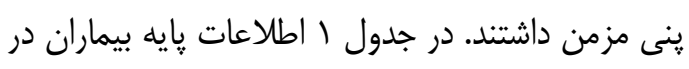
دو گروه آمده است. هيج ارتباط معنا دارى بين گروه امده مورد و شاهد بات

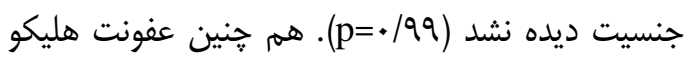

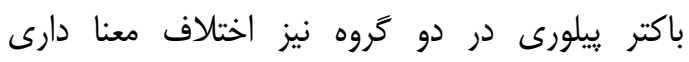
نداشت(p=•/VV).

جدول ا توزيع فراوانى اطلاعات يايه در 11 بيمار به تفكيك دو تروه مورد و شاهد

\begin{tabular}{|c|c|c|c|}
\hline Pvalue & N(\%) تحروه شاهد & N(\%) تحروه مورد & متغيرها \\
\hline.$/ \Delta \Lambda$ & $\varepsilon / \backslash \wedge \pm r / \varepsilon$. & $\Delta / V \Delta \pm \Gamma / Q \Psi$ & 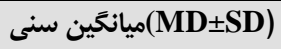 \\
\hline \multirow[t]{3}{*}{.199} & & & جنسيت \\
\hline & $r \Psi(\Delta T / \Gamma)$ & $r \Psi(\Delta T / \Gamma)$ & دختر \\
\hline & $r \mid\left({ }^{e} V / V\right)$ & $r)\left(r^{e V} / V\right)$ & 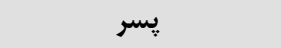 \\
\hline \multirow[t]{3}{*}{$\cdot / V V$} & & & H.Pylori \\
\hline & $g(I r / 9)$ & $\Lambda(\Lambda N / T)$ & مثبت \\
\hline & ऍ $(\Lambda \subset / \uparrow)$ & $r q(\Lambda) / \Lambda)$ & منفى \\
\hline
\end{tabular}

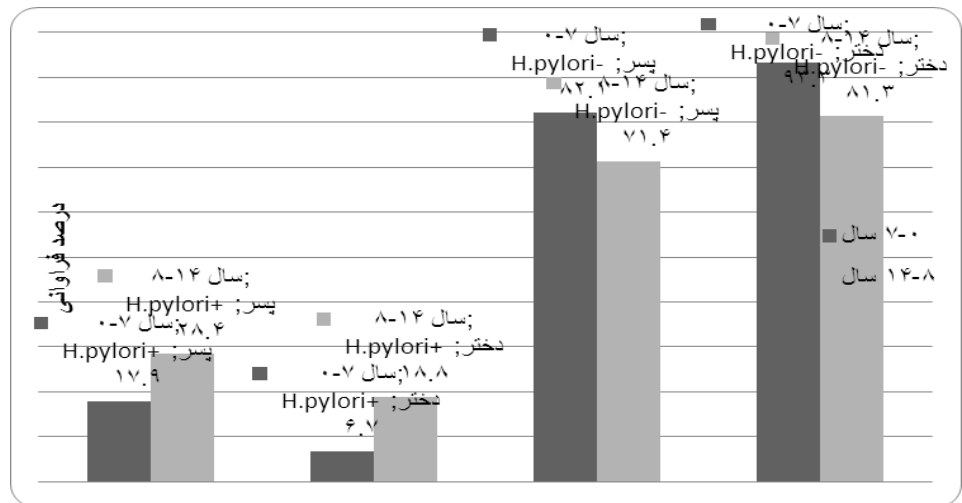

نمودار ا فراوانى عفونت هليكو باكتر ييلورى به تفكيك سن و جنس 


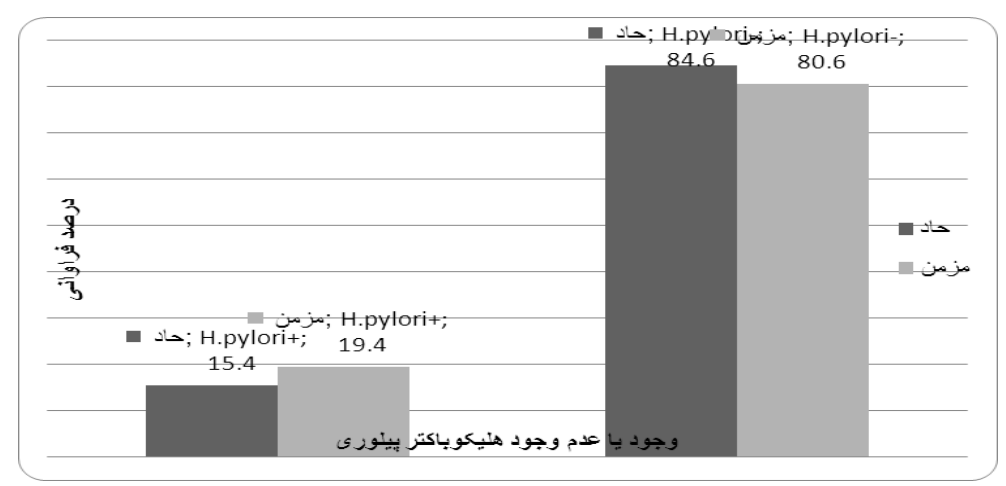

نمودار r فراوانى يوريوراى ترومبوسيتوينى حاد و مزمن با عفونت هليكوباكتر ييلورى

ياكسازى خود به خود ميكروب مى تواند اتفاق بيفتد (كه احتمالا به علت مصرف زياد آنتى بيوتيك توسط توان كودكان است). بنا بر اين هرجند ممكن است است هليكو

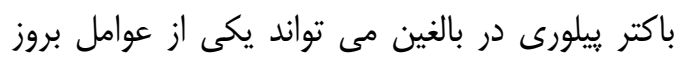

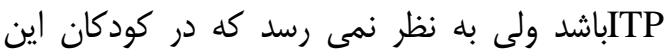

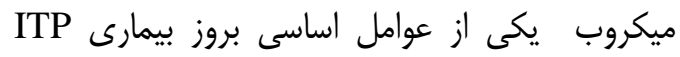

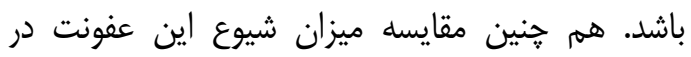

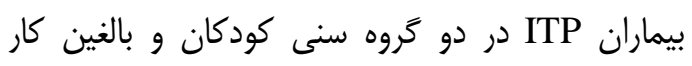
صحيحى نيست. بنابر اين امكان مقايسه مطالعه ما با كال مطالعه صورت گرفته در ايران (IV) كه در بالغين انجام شده است وجود ندارد. از سويى ديخر در تاييد اين

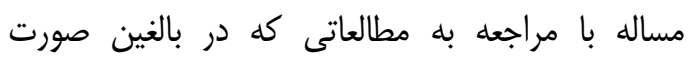

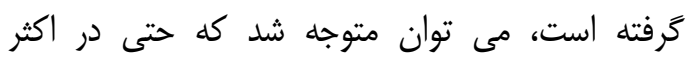

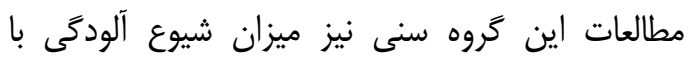

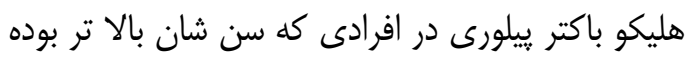

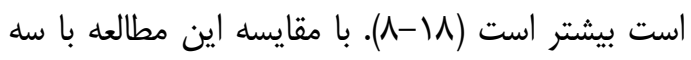
تحقيق صورت كرفته در كودكان كه به ترتيب فناند، تايوان و زاين انجام كرفته ملاحظه مى شود كه در مطالعه فنلاند در بررسى

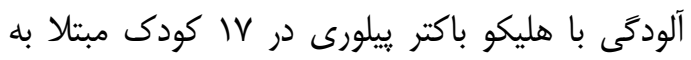

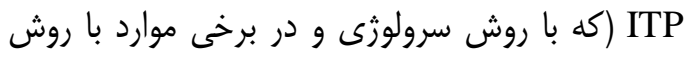

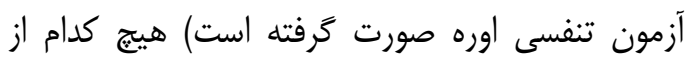
بيماران به اين عفونت مبتلا نبوده اند، در صورتى كه در

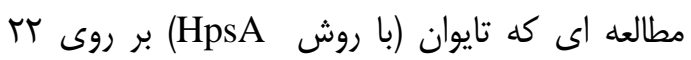

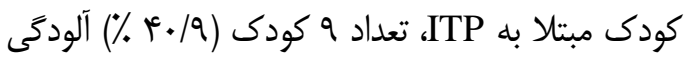
با هليكو باكتر ييلورى را نشان دادند و در مطالعه زاين

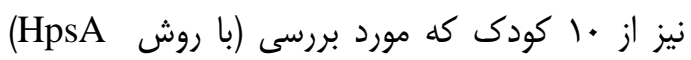

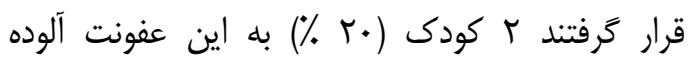
بودند. مقايسه اين سه مطالعه با مطالعه ما مشكل است

\section{بحث و نتيجه كَيرى}

مطالعات مختلفى در مورد شيوع هليكو باكتر ييلورى در مبتلايان به ITP به خصوص در بالغين صورت كرفته

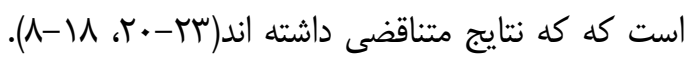
برخى از اين تحقيقات نشان داده اند كه درمان ريشه دانه

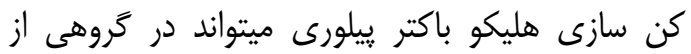

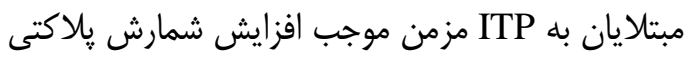

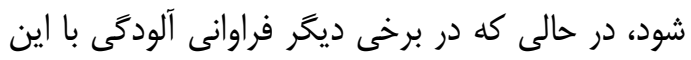

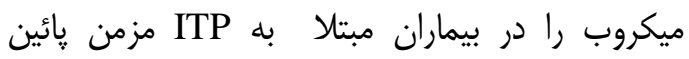

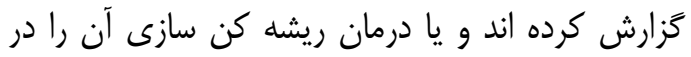
افرادى كه به اين ميكروب آلوده هستند مؤثر ندانسته

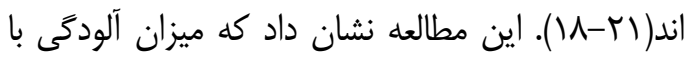

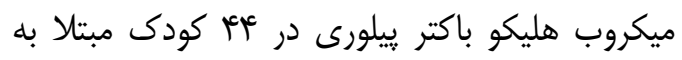
كه در بخش خون بيمارستان كودكان اميركلا

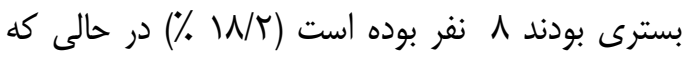

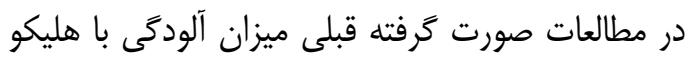

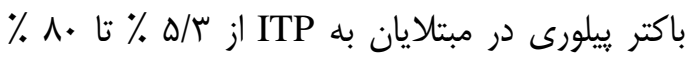

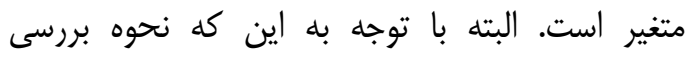

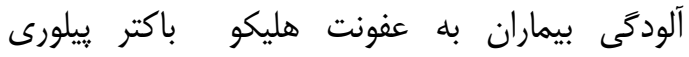

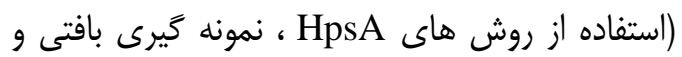

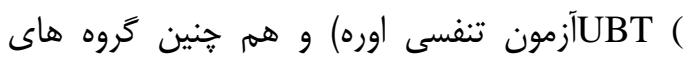
بررسى شده از نظر سنى و نزادى و جغرافيايى متفاوت آناوت

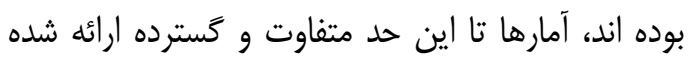

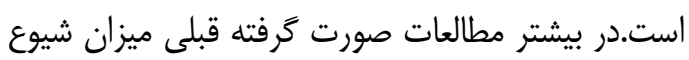

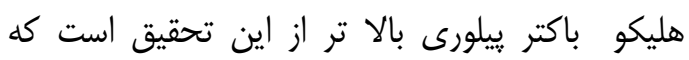

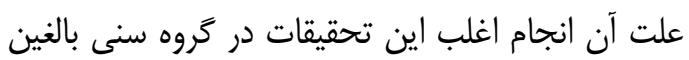

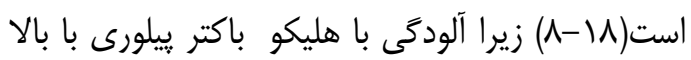

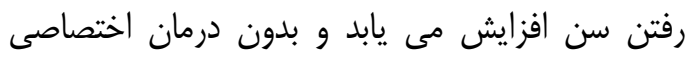
بهبود نمى يابد. اين در حالى است كه در در كودكان 
ييلورى و ترومبو سيتو ينيك يوريورا ايديو پاتيك در

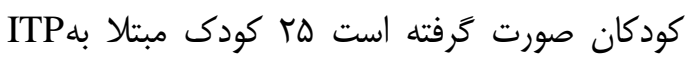

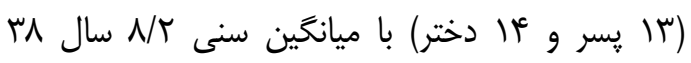

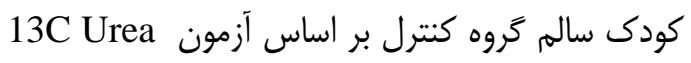
breath test

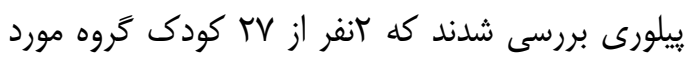
(\% V/V)

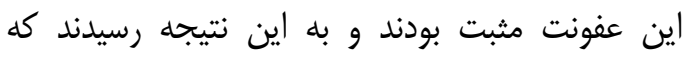

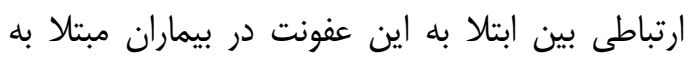

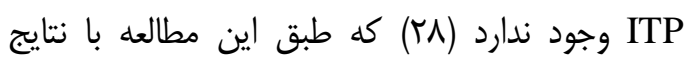
مطالعه ما كه طبق آن ارتباطى بين عفونت هليكو باكتر ييلورى و ابتلا به ITP از نظر آمارى وجود ندارد إنه

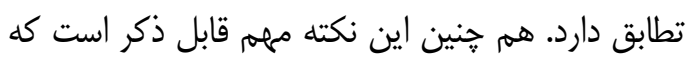

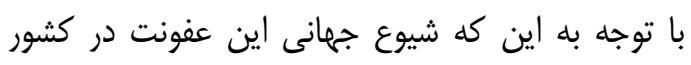

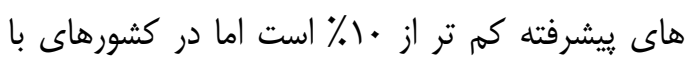

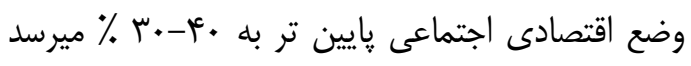

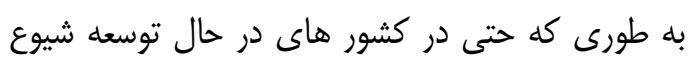

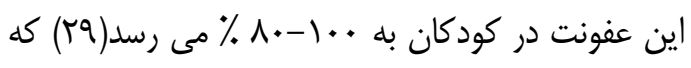

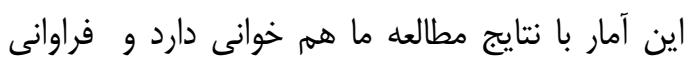

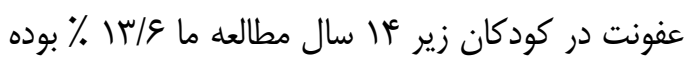
است و ذكر اين نكته كه در مطالعات مختلفى كه انجام

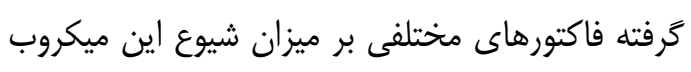
نقش دارند كه در مطالعه كه توسط اميرزاده و همكاران در سال همسا به بررسى شيوع عفونت هليكو باكتر ييلورى در كودكان با روش اليزا برروى مدفوع در شهر

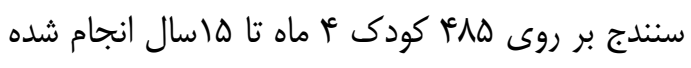
به اين نتيجه رسيدند كه كه شيوع عفونت هليكو باكتر

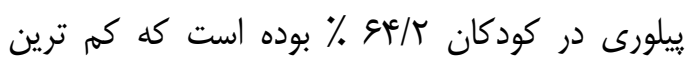

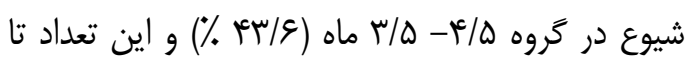

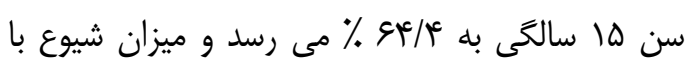

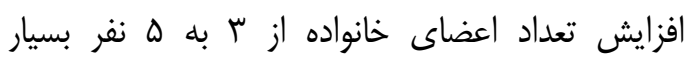

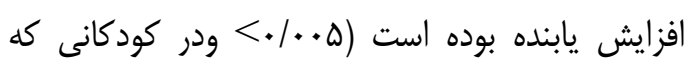
بيش از و ماه از شير مادر تغذيه شدند در مقايسه با باندان

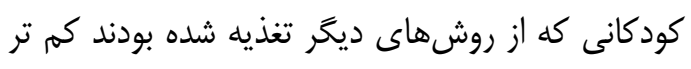

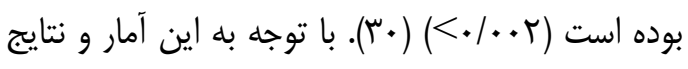

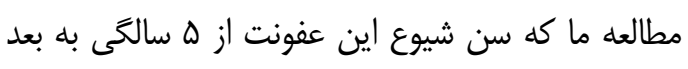
تا سنين بزرى سالى رو به افزايش مى ئ يابد قابل توجيه

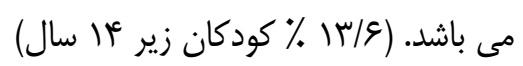

زيرا شيوع آلودگى با هليكوباكتر ييلورى در اين كشور

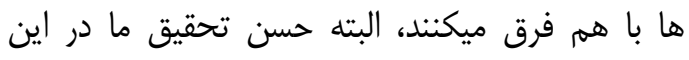
است كه تعداد نمونه از ساير مطالعات مشابه انجام

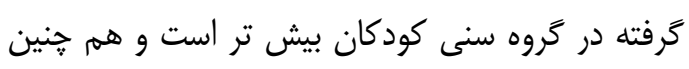
روش HpsA كه به علت حساسيت و اختصاصيت بالا و كاربردى تر بودن در كودكان در مقايسه با ساير روش بادي

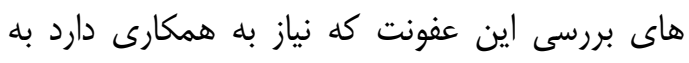

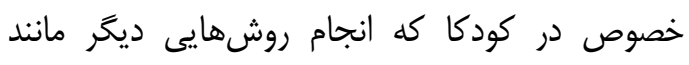

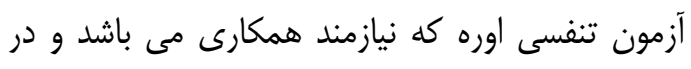
كودكان با سنين كم كه همكارى لازم را ندارند زياد

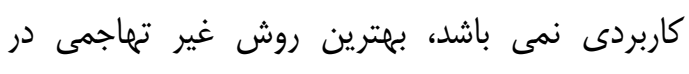

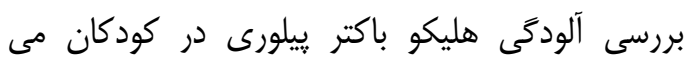

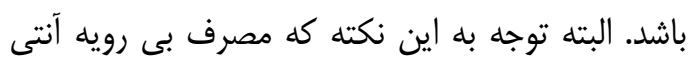

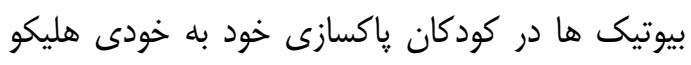

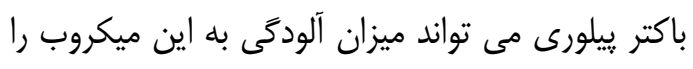
كاهش دهد.

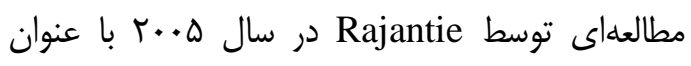
عفونت هليكو باكتر ييلورى و يوريوراى ايديو ياتيك ديك

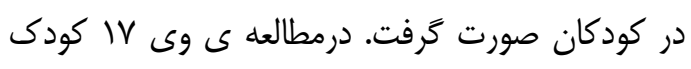

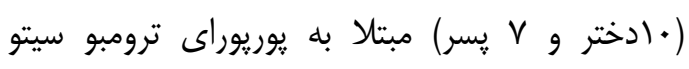

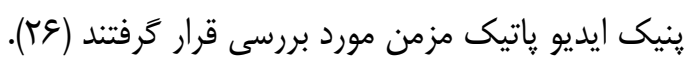
نتايج مطالعه ما با يافته هاى فوق مطابقت دارد. Shaikh ارتباط بين هليكو باكتر ييلورى و ترومبو سيتو ينيك دور ديك

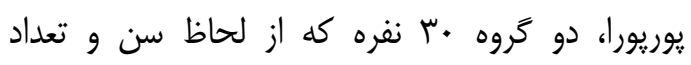
همسان سازى شده بودند را مورد بررسى قرار داد. ميزان ابتلا به عفونت هليكو باكتر ييلورى در كروه مورد مورد

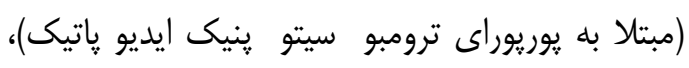

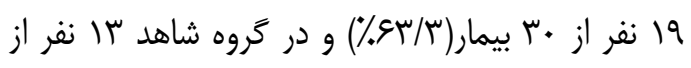

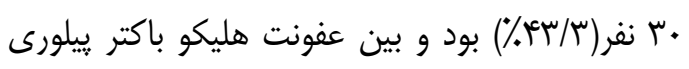

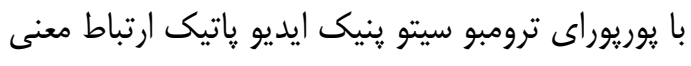

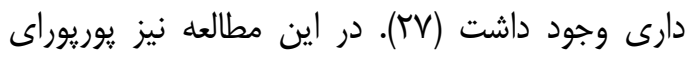

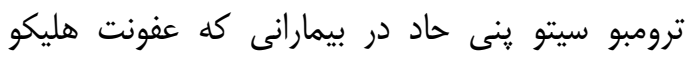

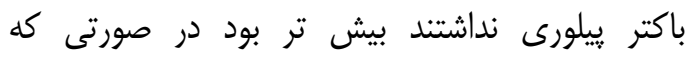

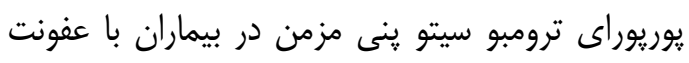
هليكو باكتر ييلورى بيشتر ديده شد. و با نتايج مطالعه

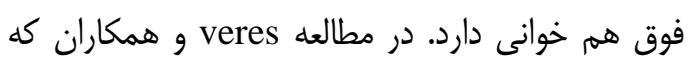

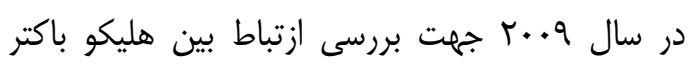




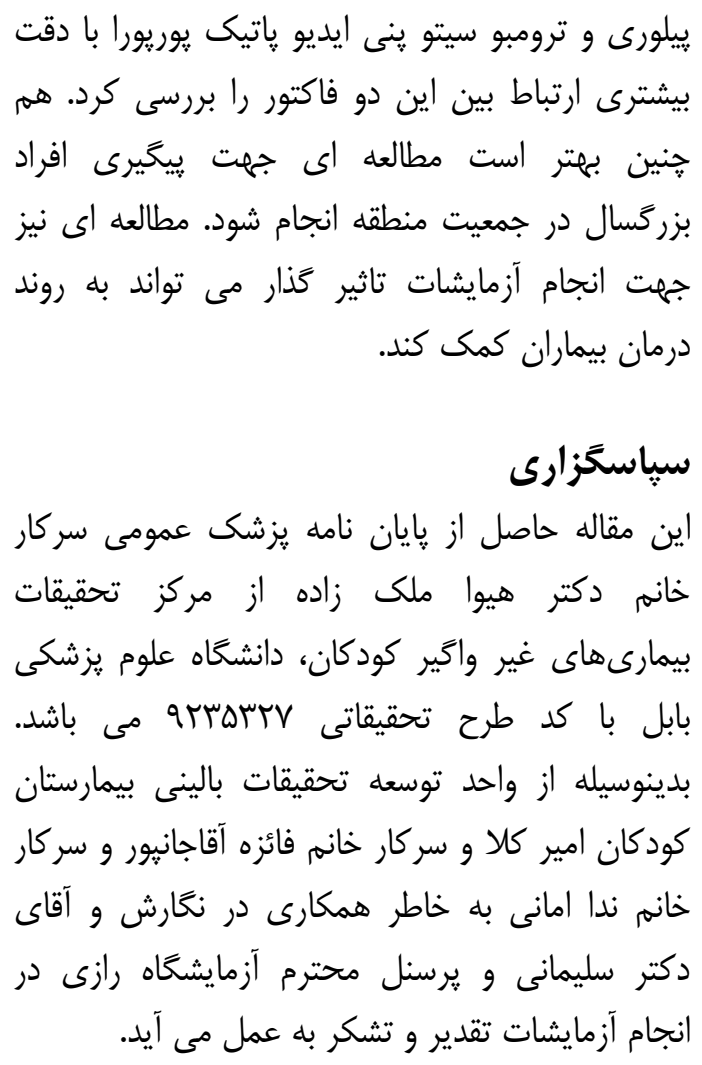

\section{References}

1.Nathan D, Ginsburg D, Orkin S, Look A. Nathan Oskis Hemathology of infancy and childhood. $6^{\text {th }}$ ed. Philadelphia WB Saunders Publication. 2003; P.325-45.

2.Mederios D, Buchanan G. Idiopathic thrombocythopenic purpura beyond consensus. Curr Opin Pediatr 2000; 12:4.

3.Zentelin PT, Savarino V, Garnero A, Accardo S, Seriolo B. Is Helicobacter pylori infection a risk factor for disease severity in rheumatoid arthritis? Gastroentology 1999;116:503-4.

4.De Luis DA, Varela C, Lacalle H, Canton $\mathrm{R}$, Argila CM, San Roman AL, et al. Helicobacter pylori infection is markedly increased in patients with autoimmune atrophic thyroiditis. J Clin Gastroenterol1998;269:259-63.

5.Figura N, Giordano N, Burroni D, Macchia G. S jogerens syndrome and H.pylori infection. Eur $\mathrm{J}$ Gastroenterol 1994;6:503-9.

6.Reinauer S, Megahed M, Goerz G, Ruzicka T, Borchard F, Susanto F, et al. Schonlein henoch purpura associated with

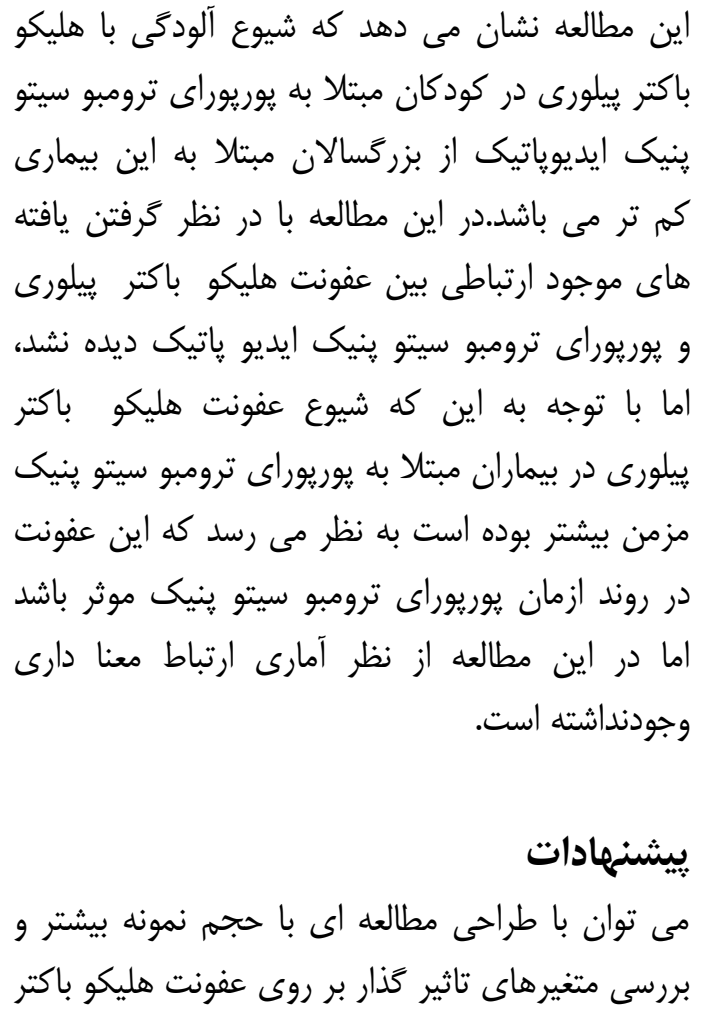

gastric H.pylori infection. J Am Acad Dermatol 1995;33:876-9.

7.Jaing TH, Yang CP, Hung IJ, Chiu CH, Chang KW. Efficacy of H.pylori eradication on platelet recovery children with idiopathic thrombocythopenic purpura. Acta Paediatr 2003;92:1153-7.

8.Gasbarrini A, Franceschi F, Tartaglione $\mathrm{R}$, Landolfi R, Pola P, Gasbarrini G. Regression of autoimmune thrombocytopenia after eradication of H.pylori. Lancet 1998;352:878.

9.Emilia G, Longo G, Luppi M, Gandini G, Morselli M, Ferrar M, et al. H.pylori eradication can induce platelet recovery in idiopathic thrombocythopenic purpura. Blood 2001;97:812-4.

10.Kohda K, Kuga T, Kogawa K, Kanisawa Y, Koike K, Kuroiwa G, et al. Effect of H.pylori eradication on platelet recovery in Japanese patients with chronic idiopathic Thrombocythopenic purpura and secondary autoimmune thrombocytopenic purpura. $\mathrm{Br}$ J Haemat 2002;118:584-8.

11.Hashino S, Mori A, Suzuki S, Izumiyama K, Kahata K. Platelet recovery 
in patients with idiopathic Thrombocythopenic purpura after eradication of Helicobacter pylori. Int $\mathbf{J}$ Hematol2003;77:188-91.

12.Veneri D, Franchini M, Gottardi M, D'Adda M. Efficacy H.pylori eradication in raising platelet count in adult with idiopathic thrombocythopenic purpura. Hematologica 2002;87:1177-9.

13.Kurtoglu E, Kayacetin E, Ugur A. H.pylori infection in patient with autoimmune thrombocytopenic purpura.World J Gastroenterol 2004;10:2113-5.

14.Veneri D, Krampera M, Franchini M. H.pylori infection and idiopathic Thrombocythopenic purpura idiopathic Thrombocythopenic purpura:description of 21 newly diagnosed cases. Hematologica 2004;89:8.

15.Sato R, Murakami K, Watanabe K, Okimoto T. Effect of H.pylori eradication on platelet recovery in patients with chronic idiopathic thrombocytopenic purpura. Arch Int Med 2004;164;1904-7.

16.Ando K, Shimamoto T, Tauchi T, Ito Y, Kuriyama Y. Can eradication therapy for H.pylori really improve the thrombocytopenia in idiopathic thrombocytopenic purpura? Int J Hematol 2003;77:239-44.

17.Vakili M, Faghihi A, Zargarkoucheh A. Recovery of thrombocytopenia in chronic idiopathic thrombocytopenic purpura. Int $\mathbf{J}$ Hematol s2004;29:120-3.

18. Michel M, Cooper N, Jean C, Frissora C. Dose H.pylori initiated or perpetuate immune thrombocytopenic purpura? Blood 2004;103:890-5.

19.Rajantie J, Klemola T. H.pylori and idiopathic thrombocytopenic purpura in children. Blood 2003;101:1660.

20.Jarque I, Andreu R, Lopiz I, Gomis F, Senen TL. Absence of platelet response after eradication of H.pylori infection in patients with chronic idiopathic thrombocytopenic purpura. $\mathrm{Br} \mathrm{J}$ Hematol 2001;115;1002-3.

21.Cherif H, Khoshkar J, Stenk L, Hellstrom P. H.pylori in a cohort of 76 patient with immune thrombocytopenic purpura. Haematologica 2005;8:94-8.

22.Hayashi H, Okuda M, Aoyagi N. H.pylori infection in children with chronic idiopathic thrombocytopenic purpura. Pediatr Int 2005;47;292-5.

23.Shimoyama T, Crabtree J. Bacterial factor and immune pathogenesis in H.pylori infection. Gut 1998;43:2-5.

24.Feigin R, Demmler G, Cherry J. Kaplan Textbook of pediatric infectious disease. $5^{\text {th }}$ ed. Philadelphia Saunders Publication. 2004;P.171-3.

25.Walker W, Durie P, Hamilton J, Watkins J. Pediatric gasterointestinal disease. $3^{\text {th }}$ ed. Hematol Canada $\mathrm{BC}$ Decker Publication.2000; P.232.

26.Arjmandirafsanjani K, Vosough $\mathrm{P}$, Salehi S, Bayanimoghaddam M. Immune thrombocytopenic purpura protests and clinical outcomes in infants. J Iran Uni Med Sci2004;11:8.

27.Sheikh KH, Ahmed S, Ayyub M, Anwar A. Association of H.pylori infection with ITP. J Pak Med Ass 2009 ; 59:660-3.

28.Veres G, Karoczkai I, Bodanszky H, Marosi A.The role of H.pylori infection in children with chronic immune thrombocytopenic purpura. Lib Med National Inst Health2009; 150:801-4.

29. Esmaili M. [A survey on the prevalence of H.pylori in children with peptic problems]. J Shahrekord Uni Med Sci1999; 4: 31-5. (Persian)

30.Amirzade N. [The Prevalence of H.pylori infection in children with elisea on stool in Sanandaj]. Faculty Nurs Midwifery2006; 4: 14-1. (Persian) 


\title{
Relationship between Helicobacter pylori Infection and Idiopathic Thrombocytopenic Purpura in Hospitalized Patients in Amirkola Children's Hospital 2012-2013
}

\author{
Mohammadpourmir $A^{l^{*}}$, Malekzadeh $H^{l}$, Tamaddoni $A^{l^{*}}$, Mahmoodi $H^{l}$
}

(Received: April 5, 2015 Accepted: April 24, 2016)

\begin{abstract}
Introduction: In different recent researches high prevalence of Helicobacter pylori infectious in adult patient with ITP disease has been reported. Furthermore, the studies have referred to increase of platelet count in some patients after eradication therapy of this infection. This problem describes the probable role of $H$. pylori in the occurrence of adult ITP. However, studies done in this case are limited in the children age group. This study aimed to determine the relationship between $H$. pylori infection and idiopathic thrombocytopenic purpura in hospitalized children in Amirkola Hospital 2012-2013.
\end{abstract}

Materials \& methods: In this crosssectional study, 88 children under 14 years old (44 case groups, 44 control group) were studied. They had been hospitalized with a diagnosis of idiopathic thrombocytopenic purpura in Amirkola Hospital (2012-2013) and their $H$. pylori infection was positive by stool antigen method. They were considered as the case group, and also a similar number of healthy children who were brought by their parents to check up on the basis of clinical and laboratory to the Amirkola infectious clinic were the control group. Their gender and acute or chronic symptoms were recorded. Data were analyzed using the statistical software SPSS V18, descriptive statistics and Chi-square test, and the significant level was set at less than 0.05 .

Findings: There were 88 children who were 42 boys (47.7\%) and 46 girls (52.3\%), respectively. The mean age of the children in this study was $5.97 \pm 3.75$ years. Among the patients, 14 patients $(15.9 \%)$ had positive $H$. pylori infection, and 74 patients (84.1\%) had negative $H$. pylori infection. Among the positive ITP patients 13 patients $(29.5 \%)$ had acute thrombocytopenic purpura and 31 patients $(70.5 \%)$ had chronic thrombocytopenic purpura. There was no significant association between the case and control groups with gender $(\mathrm{P}=0.99)$. Also, H.pylori had no significant difference between two groups $(\mathrm{P}=0.77)$.

Discussion \& conclusions: According to the results of this study, H. pylori infection has no relationship with idiopathic thrombocytopenic purpura.

Keywords: Helicobacter pylori, Idiopathic thrombocytopenic Thrombocytopenia, Children 